\title{
Human Resources as Ethical Gatekeepers: Hiring Ethics and Employee Selection
}

\author{
Salvador Villegas \\ George Fox University \\ Robert A. Lloyd \\ Fort Hays State University
}

\author{
Addison Tritt \\ Fort Hays State University
}

Edward F. Vengrouskie

The Jack Welch Management Institute

The act of hiring an individual can have considerable ethical and legal implications for an organization. To better identify the concepts that influence hiring and employment selection ethics, a review of the recent literature found several areas of importance for both academics and hiring managers alike. Past researchers claim hiring managers are influenced by the concepts of moral obligation, diversity, antidiscrimination, integrity, and employment fairness whenever they embark on hiring new personnel. Awareness and action in these areas will lead to motivating factors which can change attitudes, while allowing ethical hiring practices to shape organizational culture. The literature presents a dichotomy of understanding that when organizations use a defined ethical hiring standard, employers are more likely to recruit and hire ethical candidates. This understanding creates the assumptions that managers are obligated with the responsibility of being ethical gatekeepers for their respective organization.

\section{INTRODUCTION}

The selection and hiring of new employees seems to be a never-ending cycle for managers in all industries. Hiring managers may be looking for an applicant with experience, education, or just a great personality. Hiring managers should be aware of the ethical implications of hiring the right person, as ethics is a primary responsibility of management (Paine, 1994). Hiring managers have the difficult task of finding individuals who can fulfill the organizations needs with proper credentials, while adhering to both regulatory and internal employment operations. Beyond the legal framework involved in employment practice, a manager should be aware of the ethical responsibilities associated with hiring practices. If an organization is only as effective as its employees, then it is the hiring manager who must understand that recruiting an ethical employee is of the utmost importance for the organization (York, 
2014). The actions of just a few compromised individuals who purposefully act in an unethical fashion can ruin an entire organization's reputation (Ashkanasy, Windsor, \& Treviño, 2006). To prevent, or at least mitigate unethical behavior, the role of all hiring managers should include the responsibility of being an ethical gatekeeper for their respective organizations. Companies that choose to operate according to an internal ethical standard, should also pursue ethical hiring procedures and guiding principles (Alder \& Gilbert, 2006) to assist managers in the promoting ethical employees.

The employment laws in the United States are clear that any applicant or employee should be shielded from discrimination based on the overarching protected classes of race, gender, color, creed, religion, national origin, disability, age, or genetic information (Equal Employment Opportunity Commission, 2009). These laws have been the default standard for many managers during the hiring process. Adherence to this anti-discrimination regulation does not necessarily result in ethical hiring practices or the selection of ethical individuals. Additional regulatory requirements set forth through the Sarbanes-Oxley Act requires organizations to create and disclosure their corporate code of ethics in a public fashion to promote standards that require honest and ethical conduct, transparency in full financial reporting, and adherence to all governmental regulations (SEC, 2002). In an environment where federal regulations are setting the minimum standard of ethical practice in business administration, the role of a manager is being further directed to not only operate in a profitable manner, but also to hire ethical employees in an ethical fashion. Even as the law has set the legal employment standards for domestic companies, ethical fairness permeates these regulations with a call to go beyond the minimum (Alder \& Gilbert, 2006, York, 2014).

\section{Importance}

Hiring ethics, much like many business research topics, is of both theoretical and practical importance. Research into this topic results in a visible framework for understanding the specific character traits exhibited by candidates for open positions, while providing an ethical foundation for organizational leaders responsible for hiring. The more that is known about the subject of hiring ethics, the greater opportunity that theory has to influence practice. Many theoretical/philosophical elements influence the body of knowledge relating to this subject including human resource development (HRD), organizational diversity, descriptive leadership ethics, normative philosophies, etc. As the ethical aspects of hiring and employee selection are further researched, the body of knowledge of each of these areas will benefit. The findings of this literature review will also allow for greater guidance in creating ethical practices and procedures for hiring managers. The benefits of understanding the ethics that guide hiring practices are two-fold. By forcing ethical awareness in organizational hiring procedures, a firm can first help themselves by implementing safeguards to minimize any harmful action or inaction that can negatively impact either the organization or applicant through the employment process (Roberts, 2016). Secondly, as the ethical gatekeeper for an organization, hiring managers can put theoretical frameworks into action through the selection of ethical candidates who can complement the ethical climate of an organization. As postulated by past research, "The success and reputation of your company is determined in large part by the ethical values of your employees. Therefore, determining a candidate's personal values - not just their technical skills and education, is paramount" (York, 2014, p. 26). For the ethical longevity of an organization, it is of utmost importance to staff the organization with individuals who are also ethically minded. Research now clearly points to developing employees as an intrinsically valuable ends, and the emphasis of employees as key stakeholders under a CSR focus can lead to more profitable outcomes (Lloyd, 2017). A review of current academic literature will uncover some of the ethical issues, trends, developments, and pertinent situations surrounding recruitment and hiring of new employees.

\section{Literature Review}

Extant research demonstrates that an organization's employees are its primary source for creating a competitive advantage (Ruona \& Gibson, 2004). If this is true, then a manager must ensure that new employees are the ethical human capital and competitive advantage who can help build an organization rather than create demise. Ethical behavior in an organization does not just happen through spontaneity, 
but through specific actions and managerial declarations. The important role of managers in hiring ethically and selecting ethical candidates cannot be understated. The literature on this subject matter provides a glimpse into the many elements that are involved in the ethics of hiring new employees. Through several ideas regarding this area of business management have helped to define the ethical practices needed for ethical employee selection, some of the most common themes include ideas such as moral obligation, diversity, antidiscrimination practices, integrity based approaches, fairness/justice, and need for honest communication.

\section{Moral Obligation}

The decision to hire the right person for any vacant position is an action that should not be taken lightly. Managers have an obligation to set the ethical climate of a company that can result in strengthening relationships, forging reputations, and creating the ultimate success of the firm, all of which are dependent on managerial acknowledgment of their ethical responsibility (Paine, 1994). Additionally, past researchers have argued that not only do hiring managers have the positional power to choose one candidate and reject other applicants, but more so, managers have a moral obligation to exercise their decision in a responsible fashion (Alder \& Gilbert, 2006). A manager who disregards their obligation to be ethical in their hiring decisions, and fails to choose the best candidates, is increasing the chance of allowing bad apples to infiltrate their organization. As postulated by Ashkanasy et al. (2006), bad apples are morally flawed individuals who are predisposed to behave in an unethical manner, and when given the opportunity will do so. Every organization is susceptible to the shortcomings of employees who act in unethical or immoral ways. To be sure, ethical hiring practices and managerial safeguards may not completely prevent poor employees from gaining employment. However, a manager who acts according to a moral obligation has a potential of mitigating the threat of hiring someone that could negatively affect the organization and its stakeholders.

In response to the ethical discourse on employment practices, Lantos (1999) argues, "moral behavior builds trust, which attracts customers, employees, suppliers, and distributors, not to mention earning the public's goodwill. Conversely, immoral behavior chases these various groups away" (p. 225). Even if short-term gains created through immoral business activity are sacrificed due to ethical principles, the long-term result of operating in a moral fashion could be highly beneficial for the organization. As other researchers have also proposed, hiring managers are the responsible for ensuring that ethics are a significant priority when selecting new employees. A three-step process is suggested as a guide to assist managers in fulfilling their duty for ethical employment and hiring. First, in any hiring decision, ethical character should be identified through behavioral interview questions to better identify a candidate's individual character traits such as openness, self-discipline, and personal virtues. Second, existing business leaders and managers must demonstrate ethical activity in their mannerisms and deeds. Third, managers need to cultivate their own personal sensitivity to be able to identify and become aware of ethical situations. (Lantos, 1999).

As also defined in Rest's model of moral behavior (Johnson, 2015), there is a gap between knowing what to do and taking the actions necessary for implementation. According to Lantos (1999), if managers intentionally focus on creating ethical motivation paired with action, both for themselves and while carefully hiring employees, perhaps future press on business ethics will appear less criminal than it does today.

\section{Diversity}

The business case for organizational diversity has clearly been defined in past research. Benefits of a diverse workplace include greater innovation, higher retention, better decision making, higher quality employees, an improved public image, etc. (Johnson, 2015). Diversity in employees can mean differences based on race, nationality, sex, religion, disability, and even genetic makeup (Roberts, 2016). Additionally differences in education, experience, and values could potentially fall under the umbrella term of diversity. Notwithstanding the business case for diversity, diversity also makes sense to employers for philosophical ethical reasons. For example, hiring people of different backgrounds creates 
more good than it does harm (utilitarianism), respecting differences acknowledges the dignity of each person (deontology), promoting social justice, and reflects love of our neighbors in maximizing their unique potential (altruism) (Johnson, 2015). In terms of hiring diversity, the ethical nature of the process should not be evaluated on overall patterns, but rather on the affect that the process has on the individual being selected for the positon (Alder \& Gilbert, 2006).

Regardless of the strong moral and business reasons for seeking diversity in hiring practices, the strategy to achieve diversity must be intentional. Research shows that paying attention to the social makeup of the workforce can impact the overall motivation of the workforce (Lloyd \& Mertens, 2018). Even with the legal precedent that protected class status should not be a contributing factor to hiring decisions, for diversity in hiring to occur, some type of affirmative action policy must be implemented (Alder \& Gilbert, 2006). As defined by past research, affirmative action is "a class of public policies focused on achieving equality of opportunity, especially in the realms of tertiary education and employment, for certain historically oppressed groups" (Taylor, 2009, p. 478). As a framework for managing diversity in hiring practice, Alder \& Gilbert (2006), propose a four-part action plan to increase the diversity of an organization that consists of. He proposes that diversity begins by eradicating a hiring manager's personal bias towards job applicants by requiring diversity training. Second, he suggests removing barriers that may be limiting under-represented groups of job seekers from applying for open positions. Barriers include using only online applications that require internet access or placing help wanted ads in newspapers that are not widely read. Next, he proposes that necessary steps need to be taken to increase a diverse mix of applicants by broadening recruitment efforts such as engaging applicants from a several different schools or areas of town. Finally, he concludes that diversity should place an emphasis on favoring protected classes in the job selection process.

For diversity to take hold and change the demographic makeup of an organization, the idea of embracing difference is important for hiring managers to understand. In an environment composed of culturally diverse groups, as compared to culturally homogenous groups, a climate of inclusion can help to create a sense of comfort, that encourages all employees to apply their personal differences to specific work processes, necessary tasks, and organizational strategies (Boekhorst, 2015). Creating a diverse climate should a distinct hiring priority based on the ethical, business, and societal benefits that can be directly achieved from the contributions of people with dissimilar backgrounds. To achieve diversity requires a need to reduce both overt and unconscious discrimination in hiring.

\section{Anti-discrimination}

Refusing to hire someone based on protected class status is a blatant violation of U.S. labor laws. This includes practices that create an explicit discrimination termed by the EEOC as disparate treatment, and the practices that result in a de-facto discrimination despite intentions, termed by the EEOC as disparate impact. Even with laws and regulations, the news is continually reporting on employers who were blatant in their refusal to hire someone due to some form of discrimination. Some researchers will argue that discrimination is human (Cuilla, Martin, \& Solomon, 2014), and even with legal frameworks in place, the likelihood of eradicating manager bias is difficult, if not impossible. Other research has suggested that discrimination is not only immoral, but that hiring managers and the organizations that they represent have a moral obligation to enforce the principle of non-discrimination in employment (Demuijnck, 2009). To fulfill the moral obligation, Demuijnck (2009) postulates that firms must implement effective diversity training by setting long-term diversity objectives and by assigning specific managerial responsibilities to

support this initiative. Successful hiring procedures require an organization to be genuinely motivated to help their managers avoid discriminatory behaviors. Some managers may be intrinsically motivated avoid discriminatory behaviors, whereas others will rely on the corporate culture for guidance and structure (Lantos, 1999).

Obvious and intentional discrimination based on protected factors is much easier to identify when it happens. When discrimination occurs through subconscious stereotyping or personal bias, unforeseen problems can arise in the hiring process. In her legal analysis of employment discrimination in relation to the harm principle, Roberts (2016), builds the case of detrimental stereotyping and the negative effects 
that it can cause through employee selection and employment. In her article, the researcher discusses the idea of actions that can cause certain stereotype threats. In some situations, even mentioning that someone falls into a diverse or protected class can be harmful trigger that may create disillusionment with the organization, depressed ability, a feeling of tokenization, or even a sense of exclusion (Roberts, 2016). Among other things, Roberts (2016) argues that some stereotype triggers could also leave an organization susceptible to employment discrimination where others may not. As proposed by the author, the best way to avoid unethical stereotyping in hiring is to create stringent internal policies and procedures through self-evaluation for the purpose of minimizing the occurrence of stereotypic harms (Roberts, 2016).

Federal regulation has defined which classes are protected, however to maintain a climate of ethical hiring practices, there are other forms of discrimination that organizations should be made aware of. The literature has ample examples of ways that organizations can reduce discrimination of unprotected factors in their hiring practices, but for the sake of brevity, only a few additional examples are presented. Some researchers have found that employers are beginning to take into consideration economic factors such as likelihood of an applicant to use medical benefits, a desire to restrict the personal liberties of employees outside of work, and requiring pre-employment health screenings which can be viewed as an invasion of privacy (Ladd, Pasquerella, \& Smith, 1994). These same authors argue that " using non-job-related criteria for hiring is discriminatory and that hiring decisions should be based exclusively on the prospective employee's ability to do the job" (Ladd et al., 1994, p. 326). Some employers may try to justify this type of discrimination as a method of reducing corporate liability during hiring; however, the results of their actions are can be labeled as discriminatory and unethical. Corporate leaders and hiring managers who allow such actions to take place are a perfect example of moral disengagement by using moral justification to convince themselves that their harmful behavior is beneficial (Johnson, 2015).

Some researchers are calling for corporations to begin reducing discrimination based on appearance bias (Harvard Law Review as cited by Cuilla, Martin, \& Solomon, 2014). This research originally published in the Harvard Law Review cites several examples of how employers need to create policies that disregard personal attractiveness and unilaterally forbid pre-employment inquiries in regards to appearance (with the exception of grooming). Much of this research comes from recent studies where overweight individuals have reported being discriminated against due to their appearance rather than their ability to do the job for which they are applying. Echoing the strategy set forth by previous research, the anonymous author(s) suggest that employers need to reflect on their own practices and place emphasis on legitimate work related applicant criteria rather than consider appearance. The only way to stop this form of bias is to change the attitude of hiring managers and people in general. When managers adhere to ethical hiring practices, based in either personal values or corporate policies, they are acting with integrity.

Bias and discrimination may not always be negative, and in some cases actually benefit an applicant for a positon. In his book Everyday Bias, researcher Howard Ross (2014) explains that sometimes interviewers may instantly favor an applicant over others due to some stereotype or associated feeling. According to Ross (2014), our unconscious biases are formed either individual or collectively, and they affect every decision we make including who we interview, how we interview, hire, assign jobs, promote, or take a risk in hiring.

\section{Integrity}

When managers practice their duty of upholding the ethical identity and climate of an organization in hiring, they are exercising both moral character and integrity. Compliance with the law is not to be confused with integrity, but rather integrity is an essential element that influences every type of business decision (Johnson, 2015), including hiring. Adherence to governmental compliance acts as a guide to avoid legal repercussions, whereas taking an integrity-based approach to management goes much deeper affecting operations and behavior. In an environment that chooses to operate in an ethical manner, management will personify moral values, create an ethically supportive climate, and instill the idea of shared accountability among all employees (Paine, 1994). An organization who adheres to integrity focused guiding principles will be more likely to identify the ethical and job related skill set of potential 
applicants when determining suitability for possible employment (Paine, 1994). When hiring, employers can recruit, but should do so in a manner that is void of deception and moral transgressions (Gardner, Stansbury, \& Hart, 2010), as these types of actions would not be permissible in an integrity based approach.

During the hiring process, honest communication about the ethical expectations for the position should be communicated to all potential applicants (Evans, 2009; York, 2014). This forthcoming and public stance on ethical standards demonstrates the commitment and value placed on ethical activity within the organization. Individuals who are hired through an ethical process will most likely be appreciative of the honesty and integrity that was demonstrated prior to employment (Evans, 2009). If an organization deliberately focuses their activity to sustain a climate of integrity, this will also be reflected in both how they hire, and even more so, who they hire. Clear ethical expectations are an organizational necessity for both onboarding ethical and beneficial talent, while passing on potential bad apples. In situations like employee selection, managers and leaders should show coherence between their integrity and action (McFall as cited by Ciulla, Martin, \& Solomon, 2014). Setting a corporate ethical standard allows both employees and potential employees to see integrity as a guiding corporate principle.

\section{Fairness}

The critical concepts of fairness/justice have permeated nearly every discussion on hiring ethics within this literature review. Rawls (1971), laid out an argument for fairness as he explains how often times individuals are quick to develop rules for societal action while being ignorant to their own selfinterests. These interests affect fair distribution of both benefits and burdens for everyone, including fairness in hiring criteria (Ladd et al., 1994). Through the scope of ethical employment protocol, the goal of fairness in hiring is not just have formal access to a position, but rather to actually be considered for an open position without the blindness caused by managerial self-interest (Rawls as cited by Demuijnck, 2009). Bias undermines fairness when a manger acts in accordance with their own self-interests by intentionally withholding employment opportunities from individuals who are qualified for the position, however disregarded due to the manager's personal prejudices (Alder \& Gilbert, 2006). Organizations who choose to uphold the values of fairness and justice have earned the right to be called ethical, whereas organizational values that prioritize profits or allow for the bending of rules tend to be considered unethical (Alder \& Gilbert, 2006). In terms of acquiring new employees, fairness in the hiring process and selection of candidates is synonymous with ethical behavior.

\section{Developments \& Trends}

Existing literature suggests a need to focus on ethical theory and transform it into ethical practice (Martin \& Cullen, 2006). Researchers repeatedly call for managers and leaders to take a definitive stand in incorporating ethical hiring practices into their organizational code of ethics and employment policies. The literature shows an evolution from theoretical/philosophical concepts such as normative ethics, to justice, doing no harm, and fairness in employment. In terms of practice, equal employment opportunity laws have aided in the quest for ethical hiring practices, but the journey to true ethical hiring procedures still has quite a way to go. Based on the patterns discovered through this review, the predominant mantra from researchers is a challenge for business leaders to:

- Honestly self-reflect to recognize organizational behaviors that are less than desirable and/or unethical

- Construct core organizational values and guiding principles

- Institute ethical systems/procedures throughout the organization that affect all areas of operation, including human resource management and hiring practices. This would also include strategies like diversity training, and internal principles that avoid discrimination and bias in hiring

- Demonstrate adherence and embodiment of the organization's ethical values through corporate and managerial actions. 
- Ensure that all applicants have a clear understanding of the ethical expectations of the firm.

- Hire and onboard the most ethically qualified candidate who has the skillset needed to excel in the vacant positon.

Human nature and the ideas of personal bias and rational self-interest may always be a hurdle to cross when dealing with employee selection, but as attitudes and motivations change, perhaps learned ethical behavior would prevail. The hiring process as the first contact with an employee is the first step in inculcating an ethical climate, and is reinforced by the continuous development of that employee thereafter (Thoman \& Lloyd, 2018). This creates a paradox inasmuch as ethical hiring practices need to originate from somewhere; however, it is not always clear from where. If an organization is ethically toxic, it can begin to corrupt even the most ethical of employees by acting as a bad barrel (Linda Klebe Trevino \& Youngblood, 1990). Desjardin (2013) makes the case that managers come from the ranks of employees and in turn are charged with hiring new employees. Ethical managers beget ethical hiring practices while the resulting workforce constitution is a bevy ethical employees.

When an organization is ethical, it can still be negatively affected by the actions of immoral employees and leaders who are prone to acting in an dishonorable manner (Ashkanasy et al., 2006). Many of the researchers assume that once leaders put ethical employment procedures in place, the moral transformation of the organization will allow for better recruitment of ethically minded candidates. This idea requires further testing in practice to verify if ethical hiring policies yield ethical applicants and subsequently employees. It is reasonable to believe that this concept is valid, but until properly vetted, it too can only be classified as a theory.

As the subject for this review centered on ethical business hiring practices, the amount of crosssubject research on this matter is substantive. For example, more research needs to be conducted on the cross-cultural implications of ethical practices marshalled by human resources as well as the implementation of ethical culture during international expansion efforts (Yamamoto \& Lloyd, 2019; Vollrath et. al, 2017; Lloyd, 2016). Strictly based on the journal articles used to identify key employment components, the fields of business, philosophy, psychology, and law have all helped to contribute to the body of knowledge that shapes the understanding on this topic. Recently, researchers have been developing tools to help identify ethical values in job applicants to assist employers in hiring individuals who are morally able to uphold company ethical standards with little desire to act unethically. Researchers Cohen, Wolf, Panter, \& Insko, (2011), have presented and developed the Guilt And Shame Proneness (GASP) scale, a survey that helps to identify emotional personality traits by measuring levels of guilt and shame based on specific behaviors. In their study, these researchers found that those who measured with levels of high guilt based on their survey responses "are less likely to lie, make unethical business decisions, and engage in antisocial behaviors such as cheating, theft, vandalism, and aggression. They are also more honest and ethical negotiators' (Cohen et al., 2011, p. 963). Those who measured high in shame tend to show signs of antisocial behavior, high anxiety, and inconsistent behavior. Testing of this type is still in its infancy, however if shown to be a sufficient tool in identifying the ethical behavior of job applicants, it could one day influence hiring decisions in practice.

\section{CONCLUSION}

Several areas requiring the need for further research have been discovered. Within the constructs of this review, and in an effort to grow the body of knowledge on this subject matter, it could be of significant importance to properly investigate and create a framework to define the role and value of ethical gatekeepers. In a quick search for this original concept, no other academic literature could be found which uses this terminology. For the purpose of this review, the term "ethical gatekeeper" was loosely used to mean the individual responsible for hiring ethical individuals into the organization in an ethical manner. Much of the literature chosen focuses the importance of ethical acknowledgment and integrity to managers, however based on the need to advance research in this field, deeper exploration into 
defining ethical gatekeepers seems prudent. Even though managers use tools for testing the ethical aptitude of job candidates that create a prediction for future ethical behavior, it appears that further testing of these programs is still needed. In specific, rigorous and extensive testing of the GASP scale (Cohen et al., 2011) could help to validate this instrument prior to corporate implementation. Though human action and reaction can change from situation to situation, further exploration of this scale, and other ethical testing tools could determine effectiveness and aid hiring managers in their search of ethical employees, should that become a corporate priority. Though only briefly mentioned, it would be of academic importance to explore how hiring practices directly impact the philosophical and sociological elements of ethical climate theory - ECT (Martin \& Cullen, 2006). Further investigation into this topic would benefit the body of knowledge exploring both employee selection and ECT.

Even as ethical business operations may be a good business practice, this does not mean that it will be profitable; in fact, ethical practices may not be profitable at all (Kline, 2012). As a matter of financial precedent, it would be important to research how ethical hiring affects organizational profitability, if at all. Along the same mindset, calculating the ethical awareness, growth, and operations in a firm prior to, and after implementing an ethical hiring framework, could be beneficial to organizational leaders. The literature on the subject matter at the focus of this review is rich in information, but it has also opened the door to many areas that require further investigation. Proper and thorough research into these matters will grow the theoretical and practical understanding of how ethical hiring practices influence the many stakeholders of an organization including leaders, customers, and society at large (Alder \& Gilbert, 2006; Martin \& Cullen, 2006).

\section{REFERENCES}

Alder, G. S., \& Gilbert, J. (2006). Achieving ethics and fairness in hiring: Going beyond the law. Journal of Business Ethics, 68(4), 449-464.

Ashkanasy, N. M., Windsor, C. A., \& Treviño, L. K. (2006). Bad apples in bad barrels revisited: Cognitive moral development, just world beliefs, rewards, and ethical decision-making. Business Ethics Quarterly, 16(4), 449-473.

Boekhorst, J. A. (2015). The role of authentic leadership in fostering workplace inclusion: A Social Information Processing Perspective. Human Resource Management, 54(2), 241- 264.

Cohen, T. R., Wolf, S. T., Panter, A. T., \& Insko, C. A. (2011). Introducing the GASP scale: A new measure of guilt and shame proneness. Journal of Personality and Social Psychology, 100, 947966.

Demuijnck, G. (2009). From an implicit Christian corporate culture to a structured conception of corporate ethical responsibility in a retail company: A case-study in hermeneutic ethics. Journal of Business Ethics, 84, 387-404.

DeJardin, J. (2011). An introduction to business ethics (4th ed). New York, NY: McGraw Hill.

Evans, R. (2009). Hiring on high ethics is an essential part of the hiring process for property managers. Journal of Property Management, 74(1), 10-10.

Gardner, T. M., Stansbury, J., \& Hart, D. (2010). The ethics of lateral hiring. Business Ethics Quarterly, 20(3), 341-369.

Kline, W. (2012). Hume's theory of business ethics revisited. Journal of Business Ethics, 105(2), 163 174.

Ladd, R., Pasquerella, L., \& Smith, S. (1994). Liability-driven ethics: The impact on hiring practices. Business Ethics Quarterly, 4(3), 321-333.

Lantos, G. P. (1999). Motivating moral corporate behavior. Journal of Consumer Marketing, 16(3), 222 233.

Lloyd, R. A. (2016). CHS Country Operations' international business strategy. Journal of the North American Management Society, 10(1), 66-84.

Lloyd, R. A. (2017). The impact of CSR efforts on firm performance in the energy sector. Review of Integrative Business and Economics Research, 7(3), 25-65. 
Lloyd, R. A., \& Mertens, D. (2018). Expecting more out of Expectancy Theory: History urges inclusion of the social context. International Management Review, 14(1), 28-43.

Martin, K., \& Cullen, J. (2006). Continuities and extensions of ethical climate theory: A meta-analytic review. Journal of Business Ethics, 69(2), 175-194.

Paine, L. S. (1994). Managing for organizational integrity. Harvard Business Review. Retrieved from https://hbr.org/1994/03/managing-for-organizational-integrity

Roberts, J. L. (2016). Rethinking employment discrimination harms. Indiana Law Journal, 91(2), 393 454.

Ross, H. J. (2014). Everyday bias: Identifying and overcoming unconscious prejudice in our daily lives. United States: Rowman \& Littlefield Publishers.

Ruona, W. E. A., \& Gibson, S. K. (2004). The making of twenty-first-century HR: An analysis of the convergence of HRM, HRD, and OD. Human Resource Management, 43(1), 49- 66.

Taylor, R. S. (2009). Rawlsian affirmative action. Ethics, 119(3), 476-506.

Thoman, D., \& Lloyd, R. A. (2018). A review of the literature on human resource development: Leveraging HR as a strategic partner in the high performance organization. Journal of International \& Interdisciplinary Business Research, 5(1), 147-160.

Trevino, L. K., Weaver, G. R., \& Reynolds, S. J. (2006). Behavioral ethics in organizations: A review. Journal of Management, 32(6), 951-990.

Trevino, L. K., \& Youngblood, S. A. (1990). Bad apples in bad barrels: A causal analysis of ethical decision-making behavior. Journal of Applied Psychology, 75(4), 378-385.

Vollrath, M., Lloyd, R. A., \& Liu, Y. (2017). A new standard for global education: A case study of Duke Kunshan University. In Alphin, H. C., Lavine, J., \& Chan, R. Y. (Eds.), Exploring the Future of Accessibility in Higher Education, IGI Global, 21-36.

York, C. D. (2014). Hone in on your hiring practices. Journal of Property Management, 79(3), 26-26.

Yamamoto, K., \& Lloyd, R. A. (2019). Issues in international labor: A study of Japanese expatriates in Japan-based MNEs in the United States. In George, B., \& Roberts, J. (Eds.), The Changing Landscape of Global Business: Principles and Practices, Cambridge Scholars Publishing. 